УДК 82

\title{
ЛИЧНОСТЬ И ТВОРЧЕСТВО Ф.Р. ДЕ ШАТОБРИАНА В ХУДОЖЕСТВЕННОЙ РЕЦЕПЦИИ А.С. ПУШКИНА
}

\author{
Афанасьев Олег Игоревич \\ к. филол. н., старший преподаватель кафедры \\ русской и зарубежной литературы \\ Северо-Осетинский государственный \\ университет имени К.Л. Хетагурова
}

Аннотация: Статья посвящена проблеме эволюции отношения А.С. Пушкина к Ф.Р. де Шатобриану. В ней даётся целостная картина особенностей восприятия Пушкиным французского писателя. Рассматривается важность роли Ф.Р. де Шатобриана как личности и художника, оказавшего влияние на мировоззрение и художественный мир А.С. Пушкина. Также в статье предлагается краткий обзор данной проблемы, отражённой в литературоведении.

Ключевые слова: Пушкин, Шатобриан, Байрон, Набоков, романтизм, влияние, рецепция, эволюция, концепция литературного перевода.

\section{PERSONALITY AND CREATIVITY OF F.R. DE CHATEAUBRIAND IN THE ARTISTIC RECEPTION OF A.S. PUSHKIN}

\section{Afanasyev Oleg Igorevich}

\begin{abstract}
The article is devoted to the problem of the evolution of A.S. Pushkin's attitude to F.R. de Chateaubriand. It gives a holistic picture of the peculiarities of Pushkin's perception of the French writer. The importance of the role of F.R. de Chateaubriand as a personality and artist who influenced the worldview and artistic world of A.S. Pushkin is considered. The article also offers a brief overview of this problem, reflected in literary criticism.

Key words: Pushkin, Chateaubriand, Byron, Nabokov, romanticism, influence, reception, evolution, the concept of literary translation.
\end{abstract}


Проблема влияния Ф.Р. де Шатобриана на русскую литературу первой половины XIX века и на творчество и мировоззрение А.С. Пушкина получила широкое освещение в литературоведении, однако нельзя сказать, что эта проблема изучена до конца. Исследователи, как правило, обращали своё внимание на конкретные периоды творчества Пушкина (двадцатые или же тридцатые годы), упуская из виду целостную картину.

Не может быть никаких сомнений в престиже и популярности Шатобриана в России на протяжении всей взрослой жизни Пушкина. Сцены из «Аталы» Шатобриана украшали чашки и вазы, изготовленные в царской России в 1820-е годы. Хорошо известен факт влияния романа «Рене» на К.Н. Батюшкова. Жозеф де Местр, Шатобриан и Балланш были главными источниками вдохновения для близкого друга Пушкина, политического философа Чаадаева. Ещё в 1810 году князь П.Б. Козловский (который позже станет другом Пушкина) написал письмо Шатобриану, чтобы сообщить ему, что его «Атала» и «Рене» были «переведены в России и приняты с беспримерной жадностью» [14, с. 81]. Более того, есть письмо, которое князь Вяземский написал Шатобриану в 1839 году, когда после смерти Пушкина он послал уже пожилому писателю французский перевод статьи Пушкина «О Мильтоне и Шатобриановом переводе «Потерянного рая» [7, с. 314].

Всё это представляет собой убедительное доказательство того, что Шатобриан был крупной и удивительной литературной фигурой для большинства образованных русских на протяжении всего периода творчества Пушкина.

Что касается самого Пушкина, то в его библиотеке хранилось 26-томное брюссельское издание Шатобриана (1826-1832), все тома с художественными произведениями разрезаны. У Пушкина 17 упоминаний о Шатобриане (кроме посвященной ему статьи), 6 - в художественных произведениях, 5 - в публицистических, 2 - в письмах, 2 - в комментариях, имеются также две цитаты. В ранних редакциях «Евгения Онегина» Шатобриан упоминается в связи с кругом чтения героев: «Любви нас не природа учит, А Сталь или Шатобриан» [9, с. 428]. В «Евгении Онегине» также находится перефразированная цитата из романа Шатобриана «Рене»: «Привычка свыше нам дана, Замена счастию она» [9, с. 43]. Пушкин сам указал на эту цитату в примечаниях к своему роману.

У Шатобриана эта сентенция звучит таким образом: «И если бы я ещё имел безумие верить в счастье, то стал бы искать его в привычке» [16, с. 62]. 
Другая цитата из «Рене»: «Лишь обыденный путь ведёт к счастью» $[16$, c. 76$]$.

Эта тема взаимосвязи привычки и счастья, вероятно, была любима Пушкиным, поскольку он снова упомянул её в своём письме Кривцову от 10 февраля 1831 года [12, с. 263]. Она же приведена в «Рославлёве» [10, с. 137]. И это не случайно, так как Рене указан Пушкиным среди романов, герои которых сродни Онегину.

Кроме того, можно предположить, что через эту цитату из Шатобриана Пушкин уловил «истинный романтизм» [12, с. 148]. Ведь романтизм - это не только выражение чувств, но и разум. Однако это такой разум, который не возводят в культ, как это делали просветители.

Совершенно неправильно утверждать, что романтики полностью отрицали разумное начало в искусстве. Пушкин это уловил благодаря Шатобриану.

Привычка - это ещё и мудрость предков, которые искали счастье для всех людей через «обыденный путь», через проторённые дороги.

Интерес к теме «Пушкин и Шатобриан» возник ещё в XIX веке (Н.П. Дашкевич, Алексей Н. Веселовский, Н.А. Котляревский и др.). А с начала XX века он обострился, поскольку развернулась полемика о том, кто повлиял на Пушкина в большей степени: Байрон или Шатобриан.

Проблема непосредственного влияния Шатобриана на Пушкина, помимо того, что она осложнялась самим фактом влияния Байрона, всегда представляла особую трудность для любого пушкиниста, который хотел бы её исследовать.

У этой проблемы есть ряд причин.

Одна из них связана с давней русской традицией и всё ещё очень влиятельной, восходящей к «натуральной школе» 1840-х годов и критику В.Г. Белинскому, когда каждое литературное произведение рассматривают в первую очередь в свете его социальных и политических явлений. Например, история о лорде Байроне, яром враге королей, мученике, погибшем в борьбе за свободу Греции, делает его в высшей степени подходящим литературным предтечей для великого русского поэта с точки зрения русской прогрессивной общественности XIX века. Шатобриан же католический апологет с трактатом «Гений христианства», роялист, который отвернулся от более ранних философских позиций, выраженных в его книге «Опыт о революциях», и который, являясь министром иностранных дел во время Реставрации, сыграл 
важную роль в отправке французских войск для подавления испанского восстания. Такой Шатобриан, разумеется, совершенно неприемлем для большей части интеллигенции России XIX века. И, конечно, представить в советское время XX века взгляд на то, что Шатобриан имел более значительное влияние на Пушкина, чем Байрон, было трудно в силу идеологических причин. Не учитывались и высказывания самого Пушкина о восхищении Шатобрианом.

Однако вопрос о влиянии Шатобриана на Пушкина был серьёзно поднят в начале ХХ века В.В. Сиповским. В работе «Пушкин, Байрон и Шатобриан» Сиповский утверждает, что так называемый байронизм Пушкина объясняется влиянием шатобриановских «Атала», «Рене» и «Натчезы» [13, с. 27-32]. Этот тезис основан на сравнении этих произведений с произведениями Пушкина «Кавказский пленник» и «Цыгане».

Исследование содержит интересные идеи, но сильно омрачено неточными цитатами, что сбивает с толку, чем поддерживает основной тезис.

В 1911 году А.Л. Бем в своей работе «К вопросу о влиянии Шатобриана на Пушкина» подверг резкой критике утверждения Сиповского, обвинив его в том, что тот занизил роль воздействия Байрона на творчество Пушкина. Бем доказывает, что влияние Шатобриана на Пушкина было незначительным: «Не будь Байрона - литературное наследие Пушкина было бы иным, не будь Шатобриана - наследие Пушкина осталось бы тем же» [1, с. 163]. И Сиповский, и Бем игнорируют отношения между Шатобрианом и Байроном, которые в конце концов существовали независимо от Пушкина. Более того, они, вероятно, совершенно не знают хронологии этих отношений. «Триумфальный» вывод Бема, подхваченный и одобрительно процитированный германистом В.M. Жирмунским в книге «Байрон и Пушкин» [4, с. 53], может быть легко опровергнут третьей возможностью, а именно: если бы не было Шатобриана, творчество Байрона было бы несколько иным. Стоит отметить, что Байрон негативно отзывался о Шатобриане-политике, но выражал своё уважение Шатобриану-писателю.

Возникает искушение заподозрить Бема и Жирмунского в склонности преуменьшать роль Шатобриана из-за собственной приверженности к германистике.

В советском пушкиноведении специальных исследований на тему «Пушкин и Шатобриан» почти не появлялось. В.Л. Комарович в статье «К вопросу о жанре «Путешествия в Арзрум» [6, с. 326] обнаружил ряд 
параллелей, указывающих на пародирование Пушкиным путевых заметок Шатобриана «Путешествие из Парижа в Иерусалим», и высказал гипотезу о роли шатобриановского путевого очерка как жанрового прототипа для «Путешествия в Арзрум».

В 1960-е годы отношение к Шатобриану меняется в лучшую сторону.

Б.В. Томашевский в книге «Пушкин и Франция» посвятил три страницы Шатобриану и отношению Пушкина к нему как к личности [15, с. 159-161]. Томашевский осторожно попытался возродить теорию Сиповского о происхождении «Кавказского пленника». Обзор Томашевского об отношениях Пушкина и Шатобриана информативен, но, к сожалению, он дан в форме произвольной реконструкции. Советские представления о том, как должен относиться Пушкин к различным перипетиям политической карьеры Шатобриана в условиях Реставрации и Июльской монархии, вовлекают Томашевского в некоторые странные искажения причин и результатов революции 1830 года в соответствии с практикой замалчивания фактов в угоду идеологии.

Изменение отношения Пушкина к Шатобриану в данном случае основано не на собственном свидетельстве поэта (которое имеется в изобилии), а на политической повестке того времени.

В западной пушкинистике американский учёный Симон Карлинский в статье "Pushkin, Chateaubriand, and the Romantic Pose" [17] убедительно доказывал, что Шатобриан первым ввёл романтическую позу в европейскую литературу, следовательно, утверждал Карлинский, воздействие Шатобриана на Пушкина, учитывая этот факт, было значительнее, чем Байрона. Исследование Карлинского имеет большую ценность с точки зрения доказательной базы и привлечения ранее неизвестных материалов, но страдает несколько формальным и узким подходом к заявленной проблеме.

В 1979 году М.И. Гилелльсон, изучая статью Пушкина «О Мильтоне и Шатобриановом переводе «Потерянного рая» [3, с. 231], попытался реконструировать её недописанную часть, опираясь на эссе Шатобриана «Опыт об английской литературе», которое читал Пушкин. Гилелльсон предположил, что в эссе Пушкина прежде всего мог привлечь социально-политический аспект.

В.А. Мильчина в статье «Пушкин и „Опыт об английской литературе“ Шатобриана» [8, с. 143] решила продолжить реконструкцию незаконченной статьи Пушкина вслед за Гилелльсонном. Не оспаривая предположение 
Гиллельсона, Мильчина считает, что Пушкина в эссе Шатобриана интересовал не только социально-политический аспект, но и литературно-эстетический.

В середине 1980-х годов появилась возможность исследовать Пушкина в религиозном контексте. В работах этого времени затрагивается проблема переосмысления Пушкиным французского вольнодумного XVIII века. В связи с этим даётся новая концепция пушкинского шатобрианизма (В. Непомнящий. «Поэзия и судьба», 1987; Георгий Лесскис. «Религия и нравственность в творчестве позднего Пушкина», 1992 и др.).

«Однако как ранее мало останавливались на 30-х гг., так теперь почти не замечают 20-х», как справедливо замечает Л.И. Вольперт в своей статье «Пушкин и Шатобриан» [2, с. 452].

В этой статье Вольперт, обобщив собранный материал по проблеме пушкинской рецепции Шатобриана, пытается дать целостную картину пушкинского шатобрианизма, учитывая значимость всех периодов. Однако Вольперт совершенно не уделяет внимание концепции литературного перевода, когда касается статьи Пушкина, впрочем, оговариваясь, что это не столь важно для пушкинского восприятия Шатобриана. Но после этого ни о какой целостной картине пушкинского шатобрианизма речи быть не может.

А между тем этот аспект очень важен для понимания оценки, которую даёт Пушкин Шатобриану-переводчику.

Шатобриан берётся за перевод монументальной поэмы Джона Мильтона «Потерянный рай», которая всегда воспринималась как аллегорический эпос о революции XVII века в Англии. Однако, работая над этим переводом, Шатобриан демонстрирует новаторский и романтический подход. На сей раз он выступает не как оппонент просветительской идеологии, а как оппонент просветительского классицистического подхода к процессу литературного перевода.

Классицистический подход по сути своей был переводом вольным, особенно во Франции. Со времён правления кардинала Ришелье переводчик, создавая переводной текст, должен был исправлять недостатки оригинала, дотягивая эти оригиналы до эталонов совершенства, выставляемых классицизмом. Возьмём, к примеру, французский перевод комедии Шекспира «Много шума из ничего». Два персонажа исключаются из комедии в силу несоответствия эталонам классицизма. Для Шатобриана, казалось бы, воспитанного на французских культурных традициях, неприемлем метод 
перевода «улучшения», он даже отказывается переводить Мильтона стихами. Поэтому он переводит поэму прозой, чтобы передать малейшие нюансы мысли автора.

«Ныне (пример неслыханный!) первый из французских писателей переводит Мильтона слово в слово и объявляет, что подстрочный перевод был бы верхом его искусства, если б только оный был возможен!» [11, с. 335] пишет Пушкин в своей статье, посвящённой переводу Шатобриана.

Кроме того, Шатобриан дополняет поэму собственными размышлениями на тему революции. Несмотря на то, что Мильтон был сторонником Кромвеля и величайшим деятелем революционного правительства, объективно, по мнению Шатобриана, «Потерянный рай» показал трагедию народа, пережившего революцию. Адам и Ева - это символы английского народа, и эти персонажи оказались заложниками борьбы между Богом-королём и Кромвелем-сатаной. Вот такой оригинальной трактовкой обрастает поэма в интерпретации Шатобриана. Перевод «Потерянного рая» также был тепло воспринят в эмигрантской среде. Потому что к концу XVIII века многие французские эмигранты, чувствовали себя отщепенцами, лишёнными рая. Произведение в переводе Шатобриана оказалось созвучным их конкретным человеческим чувствам и делам.

Незадолго до смерти Пушкин, к сожалению, не успел дописать статью о шатобриановом переводе «Потерянного рая», в которой хоть и указывал на слабые стороны перевода Шатобриана, но защищал его от нападок, говоря, что этот перевод лучше классицистических «исправительных».

Уже в другой статье «Мнение М.Е. Лобанова о духе словесности как иностранной, так и отечественной» [11, с. 275] Пушкин, защищая Францию от обвинений Лобанова в нечестии и безнравственности, благоговейно перечисляет имя Шатобриана среди прошлых и нынешних французских писателей, известных своей католической ортодоксией (Фенелон, Боссюэ) и даже мистическим пылом (Паскаль, Балланш).

В прозаических текстах Пушкина 1830-х годов возрастает интерес к Шатобриану как личности и писателю. Вероятно, Пушкину была близка судьба Шатобриана, и он сравнивал его судьбу со своей. Это также связано с взаимоотношениями поэта и власти.

Что касается литературного влияния Шатобриана на Пушкина, следует вернуться к 1820-м годам. 
Распутывая нити «Рене», «Чайльд-Гарольда» и «Дон Жуана» в «Евгении Онегине», нельзя обойти вниманием третий литературный источник. Характер Онегина и его неспособность к взаимному чувству, вероятно, были подсказаны Пушкину романом «Адольф» Бенджамина Констана, писателя, по существу чуждого байроновскому направлению, хотя, как ни странно, Пушкин одно время считал его родоначальником байронизма. То, что Пушкин мог считать Констана предшественником Байрона, служит дополнительным доказательством его зависимости от французских источников, чтобы почерпнуть информацию о Байроне.

Что можно с уверенностью сказать, так это то, что Пушкина очень занимали мысли о Шатобриане, когда он писал «Евгения Онегина».

Французский писатель упоминается в романе несколько раз, особенно в более ранних черновиках и отрывках, которые были опущены в окончательной версии.

Опущенная 9 строфа первой главы «Евгения Онегина», которая обычно печатается отдельно в приложении или примечаниях, особенно актуальна для проблемы влияния Шатобриана на Пушкина.

Первоначальный набросок этой строфы (которая начинается со следующих строк: «Нас пыл сердечный рано мучит...») упоминает имена мадам де Сталь и Шатобриана и содержит идею, которая отражает уважение Пушкина к Шатобриану-мыслителю:

Нас пыл сердечный рано мучит.

Очаровательный обман,

Любви нас не природа учит,

А Сталь или Шатобриан.

Мы алчем жизнь узнать заране,

Мы узнаём её в романе,

Мы всё узнали, между тем

Не насладились мы ничем [9, с. 428].

Похожий, но только прозаический отрывок из «Гения христианства» мы находим у Шатобриана, где он рассуждает о зыбкости страстей:

«Огромное количество жизненных явлений, проходящих перед взором человека, множество книг, рассуждающих о человеке и о его чувствах, обогащают ум, но не опыт. Человек чувствует себя разочарованным, не вкусивши жизни; у него ещё есть желания, но нет более иллюзий. Воображение рисует ему богатую, полнокровную, удивительную жизнь, 
реальность же бедна, суха и непривлекательна. Сердце его полно, а окружающий мир пуст; и ничего не испытавши, он уже во всём разочарован» $[5$, c. 52].

Важность этого отрывка для раскрытия концепции романа Пушкина совершенно ясна, поскольку он подчёркивает характерную для «Евгения Онегина» ценность литературы в эмоциональном и интеллектуальном формировании определённых типов личности.

Здесь вполне можно разглядеть материал для создания образов Онегина и Татьяны.

На протяжении многих лет большая часть русской критики упорно рассматривала персонажей «Евгения Онегина» как воплощение определённых русских социальных типов 1820-х годов, точно воспроизведённых Пушкиным. Однако статья Владимира Набокова "Problems of Translation: "Onegin" in English" [18, с. 496], посвящённая проблеме перевода «Евгения Онегина» на английский язык, указывает на абсурдность принятия художественных идей за социологию. Любому, кто считает, что хандра Онегина является результатом социальных и политических обстоятельств, достаточно прочитать отрывок «О зыбкости страстей» из «Гения христианства» или отрывок из «Рене», чтобы понять, что книга Шатобриана о христианской апологии связана с «Евгением Онегиным» больше, чем «Евгений Онегин» связан с любыми реальными пороками крепостничества и самодержавия.

Этот обзор пушкинской рецепции Шатобриана можно завершить словами самого Пушкина, который незадолго до своей гибели дал Шатобриану высокую оценку: «Первый из современных французских писателей, учитель всего пишущего поколения» [11, с. 341].

\section{Список литературы}

1. Бем А.Л. К вопросу о влиянии Шатобриана на Пушкина // Пушкин и его современники. СПб.:1911. Выпуск XV. С. 146-163.

2. Вольперт Л.И. Пушкин и Шатобриан // Пушкинская Франция. Второе издание. Исправленное и дополненное. Тарту, 2010. Интернет-публикация. 570 с. [Электронный ресурс]. URL: https://ruthenia.ru/ volpert/Volpert_Pushkin_2010.pdf (дата обращения: 15.03.2021).

3. Гиллельсон М.И. Статья Пушкина «О Мильтоне и Шатобриановом переводе “Потерянного рая”» // Пушкин. Исследования и материалы. Л.: 1979. Т. 9. С. 231-240. 
4. Жирмунский B.M. Байрон и Пушкин. Пушкин и Западные литературы / В.М. Жирмунский. Л.: «Наука», 1978. 423 с.

5. Зарубежная литература XIX века // Реализм. Хрестоматия историко-литературных материалов. Учебное пособие. Сост., коммент.: Н.А. Соловьёва, А.Ф. Головенченко, Е.Г. Петраш. М.: Высшая школа, 1990. $384 \mathrm{c}$.

6. Комарович В.Л. К вопросу о жанре «Путешествия в Арзрум» // Пушкин. Временник пушкинской комиссии. М.-Л.: 1937. Выпуск 3. C. 326-338.

7. Литературное наследство // Нечаева В. П.А. Вяземский как пропагандист творчества Пушкина во Франции. М.: «Издательство АН CCCP», 1952. T. 58. 1059 c.

8. Мильчина В.А. Пушкин и «Опыт об английской литературе» Шатобриана // Пушкин. Исследования и материалы. СПб.:1995. T. XV. C. 143-154.

9. Пушкин А.С. Евгений Онегин. Драматические произведения // Полное собрание сочинений в 10 томах. Л.: «Наука», 1978. Т. 5.529 с.

10. Пушкин А.С. Художественная проза // Полное собрание сочинений в 10 томах. Л.: «Наука», 1978. Т. 6. 577 с.

11. Пушкин А.С. Критика и публицистика // Полное собрание сочинений в 10 томах. Л.: «Наука», 1978. Т. 7.545 с.

12. Пушкин А.С. Письма // Полное собрание сочинений в 10 томах. Л.: «Наука», 1979. Т. 10. 713 с.

13. Сиповский В.В. Пушкин, Байрон и Шатобриан: (Из литературной жизни Пушкина на юге России). СПб.:1899. 32 с.

14. Струве Г.П. Русский европеец. Издательство «Дело». Сан-Франциско, 1950. 164 с.

15. Томашевский Б.В. Пушкин и Франция. Л.: 1960. 501 с.

16. Шатобриан Р. Ренэ. Перевод Н. Чуйко // Шатобриан Р. Ренэ. Констан Б. Адольф. М.: Журнально-газетное объединение, 1932. С. 51-76.

17. Karlinsky S. Two Pushkin Studies: Pushkin, Chateaubriand and the Romantic Pose // California Slavic studies. 1963. № 2.

18. Nabokov V. Problems of Translation: "Onegin" in English. Partisan Review 22, no 4 (1995): 496-512.

() О.И. Афанасьев, 2021 